\title{
Nurse led shared care for patients on the waiting list for coronary artery bypass surgery: a randomised controlled trial
}

\author{
F McHugh, G M Lindsay, P Hanlon, I Hutton, M R Brown, C Morrison, D J Wheatley
}

\begin{abstract}
Objective-To evaluate the effectiveness of a nurse led shared care programme to improve coronary heart disease risk factor levels and general health status and to reduce anxiety and depression in patients awaiting coronary artery bypass grafting (CABG).

Design-Randomised controlled trial.

Setting-Community, January 1997 to March 1998.

Study groups-98 (75 male) consecutive patients were recruited to the study within one month of joining the waiting list for elective CABG at Glasgow Royal Infirmary University NHS Trust. Patients were randomly assigned to usual care (control; $n=49$ ) or a nurse led intervention programme $(n=49)$.

Intervention-A shared care programme consisting of health education and motivational interviews, according to individual need, was carried out monthly. Care was provided in the patients' own homes by the community based cardiac liaison nurse alternating with the general practice nurse at the practice clinic.

Outcome measures-Smoking status, obesity, physical activity, anxiety and depression, general health status, and proportion of patients exceeding target values for blood pressure, plasma cholesterol, and alcohol intake.

Results-Compared with patients who received usual care, those participating in the nurse led programme were more likely to stop smoking $(25 \%$ v $2 \%, \mathrm{p}=0.001)$ and to reduce obesity (body mass index $\left.>30 \mathrm{~kg} / \mathrm{m}^{2}\right)(16.3 \%$ v $8.1 \%, \mathrm{p}=0.01)$. Target systolic blood pressure improved by $19.8 \%$ compared with a $10.7 \%$ decrease in the control group $(\mathrm{p}=0.001)$ and target diastolic blood pressure improved by $21.5 \%$ compared with $10.2 \%$ in the control group $(p=0.000)$. However, there was no significant difference between groups in the proportion of patients with cholesterol concentrations exceeding target values. There was a significant improvement in general health status scores across all eight domains of the 36 item short form health survey with changes in difference in mean scores between the groups ranging from $8.1(p=0.005)$ to 36.1 $(p<0.000)$. Levels of anxiety and depression improved $(p<0.000)$ and there was improvement in time spent being physically active $(\mathrm{p}<0.000)$.

Conclusions-This nurse led shared care intervention was shown to be effective for improving care for patients on the waiting list for CABG.
\end{abstract}

(Heart 2001;86:317-323)

Keywords: coronary artery bypass grafting; coronary heart disease risk; nurse led shared care; risk reduction

Public Health, 1 Lilybank Gardens, University of Glasgow, Glasgow G12 8RZ, UK P Hanlon

Pollokshaws Medical Centre, 27 Wellgreen, Glasgow G43 1RR, UK M R Brown

Greater Glasgow Health Board, Dalian House, 350 St Vincent Street Glasgow

G3 8YZ, UK

C Morrison

University Department of Cardiac Surgery, North Glasgow University NHS Trust, 10 Alexandra Parade, Glasgow G4 0SF D J Wheatley

Correspondence to: Dr Lindsay GL1Z@clinmed.gla.ac.uk

Coronary artery bypass graft (CABG) surgery has been shown to be a highly effective intervention for the relief of angina, improving quality of life and for some patients prolonging life. ${ }^{1-4}$ There has been a 10-fold increase in CABG surgery procedures in the UK, from approximately 3000 a year in 1977, either as a single procedure or together with another cardiac procedure, to almost 25000 operations in $1995 .^{5}$ In Scotland, rates of CABG are among the highest in the UK, at 448 operations per million of the population in 1995. The national guaranteed maximum waiting time is one year with a mean waiting time on National Health Service (NHS) waiting lists in Scotland for routine CABG reported to be 201 days in $1998 .^{6}$ Generally there is no specific health care provision for patients awaiting CABG surgery. ${ }^{78}$

Patients awaiting CABG surgery have been reported to experience anxiety and depression, which have been shown to be related to increased severity of chest pain and dyspnoea ${ }^{9}{ }^{10}$ and increased myocardial ischaemia and infarction. ${ }^{11-14}$ In addition, uncorrected modifiable coronary heart disease (CHD) risk factors such as increased cholesterol, hypertension, smoking, and obesity have been reported in patients undergoing $\mathrm{CABG},{ }^{15}{ }^{16}$ despite evidence for improved mortality and morbidity for CHD patients when these factors are addressed. ${ }^{17-19}$ Furthermore, these factors have been shown to accelerate the progression of atherosclerosis in both native and graft vessels. ${ }^{20}$ Secondary prevention strategies have been shown to be effective in addressing both modifiable CHD risk factors ${ }^{21}$ and improvement of health $^{22}$ through nurse led programmes. Although the number and roles of clinical nurse specialists continue to increase, in a range of health care settings evidence for their effectiveness varies. ${ }^{23}$

This study evaluated the effectiveness of a nurse led shared care intervention for patients on the waiting list for CABG to improve CHD risk factors and general health status and to reduce levels of anxiety and depression. 


\section{Method}

The study was conducted over 15 months. Consecutive patients, identified as their name was added to the elective CABG waiting list, were randomly assigned to either the intervention or control group. All patients were assessed on entry to the study and at admission to hospital for surgery.

Patients' general practitioners were contacted by letter for consent for their patients to be recruited to the study. Subsequently, general practitioners with patients assigned to the intervention group were additionally asked whether their practice team would be willing to participate in the shared care intervention. All practices agreed to participate resulting in a total of 47 practices taking part in the study (two practices each had two patients).

Age, sex, and postcode were recorded for each patient. Tobacco smoking habit was recorded as number of cigarettes smoked per day and physical activity as minutes spent per day undertaking physical activity as noted in a seven day recall diary. Patients were weighed in light clothes without shoes to the nearest $0.1 \mathrm{~kg}$ and height was measured in centimetres allowing body mass index $\left(\mathrm{kg} / \mathrm{m}^{2}\right)$ to be calculated. Obesity was categorised according to World Health Organization recommendations. ${ }^{24}$

Blood pressure was measured in accordance with the British Hypertension Society guideline. ${ }^{25}$ Systolic blood pressure was measured as Korotkoff phase I and diastolic blood pressure as Korotkoff phase $\mathrm{V}$, each to the nearest $2 \mathrm{~mm} \mathrm{Hg}$. The average of two measurements was recorded.

Ten millilitres of venous blood was collected into a sample tube containing EDTA. Plasma cholesterol concentrations were measured at the Institute of Biochemistry, Glasgow Royal Infirmary NHS Trust using standardised protocols and internationally agreed quality assurance procedures.

General health status was assessed using the 36 item short form health survey (SF-36). ${ }^{26}$ This questionnaire measures eight domains of health: physical functioning, role limitation due to physical health problems, bodily pain, general health, energy and vitality, social functioning, mental health, and role limitations caused by mental health problems. Responses relate to health experiences in the previous four weeks. The scores are on a scale of 0 to 100: 0 is the worst possible health status and 100 the best.

The presence of anxiety and depression was assessed using the hospital anxiety and depression scale, ${ }^{27}$ which consists of 14 questions, seven relating to depression and seven to anxiety, each scored $0-3$. Responses relate to feelings in the past week only. A score of 7 or less indicates non-case, 8-10 borderline case, and 11 or above definite case for both anxiety and depression.

A short questionnaire was designed to ascertain patients' views of the service in terms of its support in making lifestyle changes, reducing anxiety for themselves and their family, improving information about forthcoming CABG, and general satisfaction with the service.
All hospital admissions while on the waiting list were recorded.

Ethics approval was obtained from the Research Ethics Committee of Glasgow Royal Infirmary NHS University Trust.

INTERVENTION

Health needs of the intervention group patients were assessed by a specialist cardiac liaison nurse to determine the content of a programme of monthly health education sessions. These sessions were carried out alternately by the liaison nurse in patients' own homes and by the general practitioner team nurse in the practice clinic.

Interventions addressing behavioural risk factors (smoking, physical inactivity, poor diet, and excess alcohol) were based on a person's readiness to change. ${ }^{28}$ Those receptive to making changes were encouraged to evaluate the positive and negative aspects of change. By endorsing positive aspects they were supported and helped to make changes to more healthy behaviours. Those who were not yet ready to change were given general advice and information.

Interventions for hypercholesterolaemia and hypertension were based on target values outlined in current guidelines. ${ }^{17}{ }^{18}$ If drug treatment was indicated the patient was referred to his or her general practitioner.

The specialist cardiac liaison nurse also provided information about the surgery, hospital stay, and recuperation period. Flexibility, in terms of the length of sessions, was allowed to ensure that each "care package" could be tailored according to needs. Patient held record cards were completed to allow the tracking of progress towards agreed goals at each session. Patients were also given the contact telephone number of the liaison nurse for general advice during normal working hours. An answer machine service was also available with all calls returned within one working day.

\section{STATISTICAL METHODS}

Summary statistics (mean and SD for continuous variables, median and interquartile range for non-normal data) were calculated for the variables recorded in both baseline and final assessments. Differences in the changes in score between the groups over the study period were compared by the independent sample paired $t$ tests for normally distributed data and by the Pearson $\chi^{2}$ test for categorical data.

\section{Results}

One hundred and twenty one (85\%) patients approached agreed to participate (intervention, $\mathrm{n}=62$, control $\mathrm{n}=59$ ).

\section{INCOMPLETE FOLLOW UP}

\section{Intervention group}

Eleven patients were withdrawn from the intervention group after random assignment and before baseline assessment for the following reasons: eight had surgery (one in a private sector hospital, seven as emergency or urgent cases); one died; one withdrew because of 
Table 1 Patient characteristic of control and intervention group at baseline assessment

\begin{tabular}{|c|c|c|}
\hline & Control $(n=49)$ & Intervention $(n=49)$ \\
\hline \multicolumn{3}{|l|}{$\operatorname{Sex}(\%)$} \\
\hline Male & 79.6 & 71.4 \\
\hline Female & 20.4 & 28.6 \\
\hline Median age (years) (interquartile range) & $63.0(42-76)$ & $61.1(35-77)$ \\
\hline Previous CABG (\%) & 0 & 2 \\
\hline Previous angioplasty (\%) & 10.2 & 10.2 \\
\hline \multicolumn{3}{|l|}{ Angiographic findings $\mathrm{n}(\%)$} \\
\hline One vessel disease & 0 & $4 \quad(8.2)$ \\
\hline Two vessel disease & $12(24.5)$ & $9 \quad(18.4)$ \\
\hline Three vessel disease & $29 \quad(59.2)$ & $30 \quad(61.2)$ \\
\hline Four vessel disease & $8 \quad(16.3)$ & $6(12.2)$ \\
\hline Diabetes mellitus (\%) & 8.2 & 10.2 \\
\hline Family history of CHD (first degree relatives) (\%) & 61.2 & 63.2 \\
\hline Previous myocardial infarction $(\%)$ & 61.2 & 67.3 \\
\hline
\end{tabular}

CABG, coronary artery bypass graft; $\mathrm{CHD}$, coronary heart disease.

attendance at a drug and alcohol rehabilitation clinic daily, and another because the person did not wish to complete the questionnaires.

A further two patients were withdrawn after baseline assessment because of admission for elective surgery within one month of that assessment. Forty nine patients, $79 \%$ of those recruited to the intervention arm, completed the study.

\section{Control group}

Four patients were withdrawn after random assignment and before baseline assessment for the following reasons: two were removed from the surgical list as unfit following cerebrovascular accidents; one died; one moved out of the area.

Six patients had their operation between one and two months after baseline assessment (four emergency or urgent and two elective) and complete data were not available for analysis. Forty nine patients, $83 \%$ of those recruited to the control group, completed the study.

The results reported relate to the remaining 49 intervention and 49 control group patients.

\section{PATIENT CHARACTERISTICS}

Patient characteristics are presented in table 1. Almost all patients were undergoing CABG for the first time. The majority of patients had triple vessel disease with a previous history of myocardial infarction in approximately two thirds of patients and a similar proportion with a family history of CHD in first degree relatives. The prevalence of diabetes mellitus was almost $10 \%$. The control and intervention groups were similar in these characteristics.
WAITING TIME

The mean (SD) waiting time in months was similar in both groups: 8.5 (2.6) months (intervention) and 8.3 (2.8) months (control). A few patients in both groups were admitted to hospital during their wait for surgery: four in the control group and one in the intervention group.

\section{SMOKING}

Table 2 shows that a significantly higher cigarette smoking cessation rate of $25 \%$ was achieved in the intervention group compared with a $2 \%$ reduction in the control group $(\mathrm{p}=0.001)$.

\section{OBESITY}

In the control group mean body mass index increased by $0.2 \mathrm{~kg} / \mathrm{m}^{2}$ but decreased in the intervention group by $1.0 \mathrm{~kg} / \mathrm{m}^{2} \quad(\mathrm{p}=0.000)$ (table 2). Table 3 shows that at baseline assessment, $69 \%$ of the control group and $51 \%$ of the intervention group were overweight. At final assessment there was a $24.5 \%$ reduction in overweight patients in the intervention group compared with a $10.2 \%$ reduction in the control group $(p=0.05)$. Among moderately obese patients, there was a $16.3 \%$ reduction in the intervention group compared with an increase of $8.1 \%$ of the control $(p=0.014)$.

PHYSICAL ACTIVITY

Mean time spent exercising (calculated as minutes per week) increased in the intervention group by $33 \%$ ( 75.4 minutes) and reduced in the control group by $16 \%$ (30.6 minutes) $(\mathrm{p}=0.000)$ at final assessment (table 2$)$.

TOTAL CHOLESTEROL

Table 2 shows that the mean total cholesterol concentration for the control group remained unchanged at $5.6 \mathrm{mmol} / 1$ between baseline and final assessment. In the intervention group, the mean total cholesterol reduced from $5.8 \mathrm{mmol} / 1$ to $5.1 \mathrm{mmol} / 1$, a significant difference between the two groups $(p=0.003)$. Approximately two thirds of all patients had a total cholesterol concentration exceeding the target of $5.0 \mathrm{mmol} / \mathrm{l}^{18}$ at baseline assessment (table 3). The percentage of control patients exceeding this target increased slightly but decreased in the intervention patients although over $60 \%$ still had cholesterol concentrations

Table 2 Mean (SD) of the main modifiable CHD risk factors

\begin{tabular}{|c|c|c|c|c|c|}
\hline Variable & Group (n) & $\begin{array}{l}\text { Baseline assessment } \\
\text { mean (SD) }\end{array}$ & $\begin{array}{l}\text { Final assessment } \\
\text { mean }(S D)\end{array}$ & $\begin{array}{l}\text { Change in } \\
\text { mean values }\end{array}$ & $p$ Value $^{\star}$ \\
\hline \multirow[t]{2}{*}{ Cigarette smokers (\%) } & Control (49) & 20 & 18 & $\mathrm{n} / \mathrm{a}$ & 0.001 \\
\hline & Intervention (49) & 27 & 2 & & \\
\hline \multirow[t]{2}{*}{ Body mass index $\left(\mathrm{kg} / \mathrm{m}^{2}\right)$} & Control (49) & $27.9(3.3)$ & $28.1(3.4)$ & 0.2 & 0.000 \\
\hline & Intervention (49) & $28.1(3.6)$ & $27.1(3.1)$ & -1.0 & \\
\hline \multirow[t]{2}{*}{ Seven day recall activity (min) } & Control (49) & $189.5(252.0)$ & $158.9(246.7)$ & -30.6 & 0.000 \\
\hline & Intervention (49) & $235.6(456.1)$ & $311.0(453.1)$ & 75.4 & \\
\hline \multirow{2}{*}{ Plasma cholesterol $(\mathrm{mmol} / \mathrm{l})$} & Control (47) & $5.6(1.0)$ & $5.6(1.0)$ & 0 & 0.003 \\
\hline & Intervention (48) & $5.8(1.0)$ & $5.1(0.7)$ & -0.7 & \\
\hline \multirow[t]{2}{*}{ Systolic BP (mmHg) } & Control (45) & $138.9(17.0)$ & $138.9(16.5)$ & 0 & 0.000 \\
\hline & Intervention (48) & $135.3(17.9)$ & $126.2(13.5)$ & -9.1 & \\
\hline \multirow[t]{2}{*}{ Diastolic BP (mmHg) } & Control (45) & $79.5(9.2)$ & $82.3(10.8)$ & 2.8 & 0.048 \\
\hline & Intervention (48) & $74.6(10.7)$ & $69.2(8.5)$ & -5.4 & \\
\hline
\end{tabular}

*The $\mathrm{p}$ value was based on the probability of a difference occurring by chance in the change in mean scores from baseline to final assessment between the intervention and control groups. Continuous variables presented as mean (SD). Categorical variables presented as percentage of patients. BP, blood pressure; $n / a$, not applicable. 
Table 3 Changes in percentage of patients with CHD risk factors above recommended target levels

\begin{tabular}{|c|c|c|c|c|c|}
\hline \multirow[b]{2}{*}{ CHD risk factor } & \multirow{2}{*}{$\begin{array}{l}\text { Group Control } n=49 \\
\text { Intervention } n=49\end{array}$} & \multicolumn{2}{|c|}{$\%$ above target } & \multirow[b]{2}{*}{ Difference (\%) } & \multirow[b]{2}{*}{$p$ Value ${ }^{*}$} \\
\hline & & Baseline & Final & & \\
\hline \multirow[t]{2}{*}{ Current cigarette smoker } & Control & 20 & 18 & -2 & \multirow[t]{2}{*}{0.001} \\
\hline & Intervention & 27 & 2 & -25 & \\
\hline \multirow[t]{2}{*}{$\mathrm{BMI} \geqslant 25-<30.0 \mathrm{~kg} / \mathrm{m}^{2}$} & Control & 69.4 & 59.2 & -10.2 & \multirow[t]{2}{*}{0.050} \\
\hline & Intervention & 51.0 & 26.5 & -24.5 & \\
\hline \multirow[t]{2}{*}{$\mathrm{BMI} \geqslant 30 \mathrm{~kg} / \mathrm{m}^{2}$} & Control & 14.3 & 22.4 & 8.1 & \multirow[t]{2}{*}{0.014} \\
\hline & Intervention & 26.5 & 10.2 & -16.3 & \\
\hline \multirow[t]{2}{*}{ Total cholesterol $\geqslant 5.0 \mathrm{mmol} / 1$} & Control & 66.0 & 71.4 & 5.4 & \multirow[t]{2}{*}{0.306} \\
\hline & Intervention & 75.0 & 64.6 & -10.4 & \\
\hline \multirow[t]{2}{*}{ Systolic BP $\geqslant 140 \mathrm{~mm} \mathrm{Hg}$} & Control & 44.9 & 55.6 & 10.7 & \multirow[t]{2}{*}{0.001} \\
\hline & Intervention & 46.9 & 27.1 & -19.8 & \\
\hline \multirow{2}{*}{ Diastolic $\mathrm{BP} \geqslant 90 \mathrm{~mm} \mathrm{Hg}$} & Control & 16.3 & 37.8 & 21.5 & \multirow{2}{*}{0.000} \\
\hline & Intervention & 12.2 & 2.0 & -10.2 & \\
\hline
\end{tabular}

$\star$ The $\mathrm{p}$ value was based on the probability of a difference occurring by chance in the change in mean scores from baseline to final assessment between the intervention and control groups.

exceeding the target at final assessment. The changes in percentage of patients exceeding target in the intervention and control groups during the study was not significant $(\mathrm{p}=0.306)$.

\section{BLOOD PRESSURE}

The mean systolic blood pressure remained unchanged at $139 \mathrm{~mm} \mathrm{Hg}$ in the control group but reduced significantly in the intervention group from 135 to $126 \mathrm{~mm} \mathrm{Hg}(\mathrm{p}=0.000)$ (table 2). Mean diastolic blood pressure increased slightly in the control group from $79 \mathrm{~mm} \mathrm{Hg}$ at baseline to $82 \mathrm{~mm} \mathrm{Hg}$ at final assessment, but there was a significant reduction in the intervention group from $75 \mathrm{~mm} \mathrm{Hg}$ to $69 \mathrm{~mm} \mathrm{Hg}(\mathrm{p}=0.048)$. Patients were classified as being hypertensive if either the systolic blood pressure was $140 \mathrm{~mm} \mathrm{Hg}$ or above, or the diastolic blood pressure was $90 \mathrm{~mm} \mathrm{Hg}$ or above. ${ }^{18}$ According to these criteria, approximately half of the patients in both groups had increased systolic blood pressure at baseline. This was significantly reduced at final assessment to $27.1 \%$ of intervention group patients but the percentage of control patients achieving target blood pressure increased by $10.7 \%$ (table 3). Although the proportion of patients with increased diastolic blood pressure at baseline assessment was smaller (12\% in the intervention group and $16 \%$ in the control group), there was a pronounced deterioration in the control group at final assessment with almost
$38 \%$ of patients exceeding target. There was a corresponding improvement of approximately $10 \%$ in intervention group patients.

GENERAL HEALTH STATUS

Table 4 shows the mean scores for the SF-36 domains for both groups at baseline and before surgery. At baseline assessment, the scores for both groups were generally low $(<50 \%$ of maximum). The magnitude of the scores was similar in both groups across the eight health domains. Physical role limitation was most negatively affected and mental health least. On final assessment the control group mean scores in every health domain deteriorated while in contrast mean scores for the intervention group improved; these changes were significant for all domains.

\section{ANXIETY AND DEPRESSION}

Definite cases of anxiety at baseline were recorded in $39 \%$ of the control group and $45 \%$ of the intervention group, which increased to $89 \%$ in the control group during the study. A large and significant reduction (41\%) was seen in the intervention group. Mean anxiety scores increased from 9 to 13 in the control group but reduced from 10 to $8(\mathrm{p}=0.000)$ in the intervention group in keeping with the changes in the number of definite cases.

Definite cases of depression were not so evenly distributed within the two groups at baseline: $51 \%$ definite cases in the intervention

Table 4 Mean (SD) 35 item short form health survey (SF-36) scores at baseline and final assessment and mean changes in scores between baseline and final assessment in control and intervention groups

\begin{tabular}{|c|c|c|c|c|c|}
\hline \multirow[b]{2}{*}{ SF-36 domain } & \multirow{2}{*}{$\begin{array}{l}\text { Group Control } n=49 \\
\text { Intervention } n=49\end{array}$} & \multicolumn{2}{|c|}{ Mean (SD) score } & \multirow{2}{*}{$\begin{array}{l}\text { Mean change } \\
\text { in score }\end{array}$} & \multirow[b]{2}{*}{$p$ Value ${ }^{*}$} \\
\hline & & Baseline & Final & & \\
\hline \multirow[t]{2}{*}{ Physical function } & Control & $31.1(24)$ & $24.3(25)$ & -6.8 & 0.005 \\
\hline & Intervention & $36.7(26)$ & $38.0(27)$ & 1.3 & \\
\hline \multirow{2}{*}{ Physical role limitation } & Control & 23.5 (37) & $11.2(28)$ & -21.3 & 0.003 \\
\hline & Intervention & $14.8(31)$ & $22.2(37)$ & 7.4 & \\
\hline \multirow[t]{2}{*}{ Emotional role limitation } & Control & $32.6(42)$ & $22.4(36)$ & -10.2 & 0.000 \\
\hline & Intervention & $36.0(46)$ & $61.9(46)$ & 25.9 & \\
\hline \multirow{2}{*}{ Social functioning } & Control & $45.5(31)$ & $32.3(27)$ & -13.2 & 0.000 \\
\hline & Intervention & $46.7(31)$ & $54.2(30)$ & 7.5 & \\
\hline \multirow[t]{2}{*}{ Mental health } & Control & $60.2(23)$ & $47.5(23)$ & -12.7 & 0.000 \\
\hline & Intervention & $56.7(24)$ & $68.7(20)$ & 12.0 & \\
\hline \multirow[t]{2}{*}{ Energy and vitality } & Control & $34.4(23)$ & $21.5(21)$ & -12.9 & 0.000 \\
\hline & Intervention & $29.4(23)$ & $36.5(21)$ & 7.1 & \\
\hline \multirow{2}{*}{ Pain } & Control & $48.0(27)$ & $38.0(25)$ & -10.0 & 0.000 \\
\hline & Intervention & $48.4(27)$ & $54.0(26)$ & 5.6 & \\
\hline \multirow[t]{2}{*}{ General health perception } & Control & $37.1(24)$ & $33.1(22)$ & -4.0 & 0.000 \\
\hline & Intervention & $34.2(19)$ & $43.7(20)$ & 9.5 & \\
\hline
\end{tabular}

*The $\mathrm{p}$ value was based on the probability of a difference occurring by chance in the change in mean scores from baseline to final assessment between the intervention and control groups. 
Table 5 Patient satisfaction: questions, number of patients rating each response category

\begin{tabular}{lllll}
\hline Question & $\begin{array}{l}\text { Yes, } \\
\text { a lot }\end{array}$ & $\begin{array}{l}\text { Yes, } \\
\text { a little }\end{array}$ & $\begin{array}{l}\text { No, not } \\
\text { at all }\end{array}$ & $\begin{array}{l}\text { Not } \\
\text { applicable }\end{array}$ \\
\hline $\begin{array}{l}\text { Did the programme help you make changes to your } \\
\text { diet? (n=46) }\end{array}$ & 31 & 15 & 0 & 0 \\
$\begin{array}{l}\text { If you were smoking did the programme help you to } \\
\text { stop? (n=13) }\end{array}$ & 11 & 2 & 0 & 0 \\
$\begin{array}{l}\text { Do you feel that seeing a nurse regularly helped you } \\
\text { feel less anxious during your wait? (n=49) }\end{array}$ & 46 & 3 & 0 & 0 \\
$\begin{array}{l}\text { Did the programme help your family feel less anxious } \\
\text { during your wait? (n=49) }\end{array}$ & 32 & 13 & 0 & 4 \\
$\begin{array}{l}\text { Do you feel better informed about your surgery than } \\
\text { before joining the study? (n=49) }\end{array}$ & 47 & 2 & 0 & 0 \\
$\begin{array}{l}\text { Do you feel that this service was worthwhile and } \\
\text { would be an improvement for future patients? } \\
\text { (n=49) }\end{array}$ & 48 & 1 & 0 & 0 \\
\hline
\end{tabular}

group and $28 \%$ in the control group. A significant difference was found between the two groups over the study period with an $85 \%$ increase in definite depression within the control group at final assessment but a 64\% reduction in the intervention group. Mean scores for depression rose from 8 to 10 in the control group but reduced from 8 to 7 in the intervention group $(\mathrm{p}=0.000)$.

\section{PATIENT SATISFACTION}

Table 5 presents the results of the patient satisfaction questionnaire completed by all intervention patients on admission for surgery. Overall, patients were satisfied with the service and reported that it improved levels of information about forthcoming CABG, was supportive in making lifestyle changes, and helped reduce levels of anxiety for themselves and their family.

\section{Discussion}

This study has shown that a nurse led programme of shared care for patients awaiting bypass surgery can effectively improve CHD risk factors including smoking status (table 2) and general health status (table 4) and can reduce anxiety and depression. The improvement in smoking cessation was greater than reported in other intervention studies, including any CHD patient group, of Campbell and colleagues, ${ }^{21}$ and the SHIP (Southampton heart integrated care project. ${ }^{29}$ The deleterious effects of smoking on atherosclerosis have been established clearly. ${ }^{30}$ Furthermore, long term mortality rates following CABG are significantly increased for patients who continue to smoke compared those who stop. ${ }^{31}$

The majority of patients in both groups had cholesterol concentrations greater than the recommended value ${ }^{18}$ but the proportion was similar to results reported in surveys of prevalence of uncorrected risk factors in patients with established CHD. ${ }^{15}{ }^{16}$ There was a trend for a reduction in the percentage of patients exceeding target concentrations in the intervention group during the programme but this did not reach significance.

The scores for general status (SF-36) were low in both groups at baseline assessment compared with the general population and other CHD patient groups. ${ }^{22}{ }^{25}$ However, in the intervention group, there were improvements in scores for all health domains during the study, particularly in emotional role limitation and mental health, while health status in the control group showed an overall pattern of deterioration (table 4). Levels of anxiety and depression were high at baseline assessment in both groups. Large improvements were documented in the intervention group for both anxiety and depression compared with an increase in definite cases of anxiety and depression in the control group. It is perhaps not surprising that mental health, emotional issues, and anxiety and depression were problem areas for patients with symptomatic $\mathrm{CHD},{ }^{32}$ but it is encouraging to note that they can be addressed by the intervention used in this study. While anxiety and depression may not be a problem for CHD patient groups in general, ${ }^{22}$ there were particular circumstances for patients awaiting CABG. It was uncommon for patients to be reviewed by their cardiologist during this time. In addition, the general practice team may not necessarily be aware that a patient is on the waiting list for CABG given that for any particular general practice list, there may be only one or two patients at any one time. The length of wait and uncertainty of date of surgery are likely to be contributing factors together with the fact that many patients have been reported to have heightened perceptions of their risk of myocardial infarction while in the "queue". 33

Results from the evaluation of nurse led care programmes aimed at improving the secondary prevention management of patients with established CHD have varied. In the SHIP study ${ }^{29}$ intervention by a cardiac liaison nurse immediately after myocardial infarction or diagnosis of angina improved follow up but did not change health outcome from secondary prevention measures or change quality of life compared with usual care. In a randomised controlled trial conducted in north east Scotland ${ }^{21}$ most patients with a diagnosis of CHD gained at least one effective component of secondary prevention. It was estimated that these improvements would translate into a reduction in cardiovascular events and mortality of up to one third.

Our study differed from the SHIP study ${ }^{29}$ in that the liaison nurse was actually delivering the intervention in partnership with the primary care nurses rather than just coordinating existing services. Another important difference in this study was that the intervention was more intensive than in the other trials. In common with other evaluative surveys of clinical nurse specialists, ${ }^{34}{ }^{35}$ high levels of satisfaction with care were reported.

However, the most fundamental difference in this study may be that of the patient group itself. This was an important group of patients to target. Patients on the waiting list for CABG surgery may be more motivated to make lifestyle changes than other patients with CHD. According to behavioural change theory ${ }^{28}$ this may provide a receptive mind set for making effective change. This approach to behavioural counselling has been used in another secondary prevention study with some level of success, although this was limited in the area of smoking cessation. ${ }^{36}$ 
As the roles and responsibilities of nurses expand, such a shared care scheme shows that nursing interventions can effectively improve the management of patient care. This, in the main, was achieved through the coordination of existing resources, improved communication, and the implementation of evidence based guidelines. ${ }^{17}{ }^{18}$ The improvements documented for patients participating in the programme showed that this group of patients achieved positive lifestyle changes. It is difficult to attribute behavioural change to any one particular factor as it is likely to be multifactorial, but it seems reasonable to suggest that the shared care scheme provided a necessary framework and support for these patients to effect change. Shared care models of care have been reported to be effective in the management of other chronic diseases such as asthma ${ }^{37}$ and diabetes mellitus. ${ }^{38}$ However, for patients with $\mathrm{CHD}$, there remains scope to improve medical and lifestyle aspects of secondary prevention.

\section{LIMITATIONS}

Data were collected by the liaison nurse who knew the randomisation status of the patients. However, the majority of measures were clinical or laboratory measurements and the subjective assessments such as the SF-36 and the hospital anxiety and depression scales were completed by the patient before review. Blood pressure was measured with a calibrated sphygmomanometer. The same nurse measured all blood pressures, thus eliminating observer variation. However, to address the issue of digit preference, an experienced cardiac specialist nurse conducted the study and we anticipate that any imprecision in readings would therefore be minimal.

The inaccuracy of self report is always a problem in assessing adverse lifestyle behaviours such as smoking habit or excessive alcohol intake. However, only one person in the control group reported giving up, which suggests that inaccurate reporting within this group is unlikely. It cannot be ruled out that patients wanting to provide a favourable response to the liaison nurse may in part explain the high levels of reported smoking cessation. However, we feel that this is a limited concern given that it is difficult to conceal continued smoking during such an intensive programme over a considerable period of time.

\section{CONCLUSIONS}

Secondary prevention shared care for patients with $\mathrm{CHD}$ during the waiting time for $\mathrm{CABG}$, involving a specialist cardiac nurse and community nurses, with the support of medical practitioners was shown to provide effective care management. Management of CHD risk factors, anxiety and depression, and patients' perception of their general health status all improved. In addition, the health of patients who were not randomly assigned to the intervention actually deteriorated as assessed by the outcome measures used in this study.
1 European Coronary Surgery Study Group. Long-term results of prospective randomised study of coronary artery bypass surgery in stable angina pectoris. Lancet 1982;ii: $1173-80$.

2 Coronary artery surgery study (CASS). A randomised trial of coronary artery bypass surgery. Survival data. Circulation 1983;68:939-50

3 Varnauskas E. Twelve-year survival in the randomised European coronary surgery study. $N$ Engl f Med 1988;319: 332-7.

4 Alderman EL, Bourassa MG, Cohen LS, et al. Ten-year follow-up of survival and myocardial infarction in the randomised coronary artery surgery study. Circulation 1990; 82:1629-46.

5 Society of Cardiothoracic Surgeons of Great Britain and Ireland. UK cardiac surgical register 1995/6. London: Society of Cardiothoracic Surgeons of Great Britain and Ireland, 1997:8-12.

6 Pell JP, Pell ACH, Norrie J, et al. Effect of socioeconomic deprivation on waiting time for cardiac surgery: retrospective cohort study. BMf 2000;320:15-8.

7 Mark J, Lockhart K, McMeeken K, et al. How well do we support our patients between angiography and bypass surgery? Coron Health Care 1997;1:18-21

8 Bengston A, Herlitz J, Karlsson T, et al. The epidemiology of a coronary waiting list: a description of all the patients. $\mathcal{F}$ Intern Med 1994;253:263-9.

9 Bengston A, Herlitz J, Karlsson T, et al. Distress correlates with the degree of chest pain: a description of patients waiting revascularisation. Heart 1996;75:257-60.

10 Underwood MJ, Firmin RK, Jehu D. Aspects of psychological and social morbidity in patients awaiting coronary artery bypass grafting. Br Heart $\mathcal{F}$ 1993;69:382-4.

11 Gullette EC, Blumenthal JA, Babyak M, et al. Effects of mental stress on myocardial ischaemia during daily life. $7 A M A$ 1997;277:1521-6.

12 Gottdiener JS, Krantz DS, Howell RH, et al. Induction of silent myocardial ischaemia with mental stress testing: relationship to the triggers of ischaemia during daily life activitionship to the triggers of ischaemia during daily life activi-
ties and to ischaemic functional severity. $\mathscr{~} \mathrm{Am}$ Coll Cardiol 1994;24:1645-51.

13 Deanfield JE, Shea M, Kensett M, et al. Silent myocardial ischaemia due to mental distress. Lancet 1984;ii:1001-5.

14 Barry J, Selwyn AP, Nabel EG, et al. Frequency of ST segment depression produced by mental stress in stable angina pectoris from coronary artery disease. Am $\mathcal{F}$ Cardiol 1988;61:989-93.

15 Bowker TJ, Clayton TC, Ingham J, et al. A British Cardiac Society survey of the potential for the secondary prevention of coronary disease: ASPIRE (action on secondary prevention through intervention to reduce events). Heart 1996;75: 334-42.

16 Lindsay GM, Tait GW, Lorimer AR, et al. Modifying cardiovascular risk factors after CABG. Audit Gen Pract 1995; Nov/Dec: 13-7.

17 Pylorala K, De Backer G, Graham I, et al. Prevention of coronary heart disease in clinical practice. Recommendations of the Task Force of the European Society of Cardiology, European Atherosclerosis Society and European Society of Hypertension. Eur Heart f 1994;15:1300-31.

18 Wood D, Durrington P, Poulter N, et al. on behalf of the societies. Joint British recommendations on prevention of coronary heart disease in clinical practice. Heart 1998; 80(suppl 2):S1-29.

19 Moher M, Schofield T, Weston S, et al. Managing established coronary heart disease. BMF 1997;314:69-70.

20 Lytle BW. The clinical impact of atherosclerotic saphenous Lytle BW. The clinical impact of atherosclerotic saphenous
vein to coronary artery bypass grafts. Semin Thorac Cardiovasc Surg 1994;6:81-6.

21 Campbell NC, Ritchie LD, Thain J, et al. Secondary prevention in coronary heart disease : a randomised trial of nurse led clinics in primary care. Heart 1998;80: 447-52.

22 Campbell NC, Thain J, Deans HG, et al. Secondary prevention clinics for coronary heart disease: randomised trial of effect on health. BMF 1998;316:1434-7.

23 Hobbs R, Murray ET. Editorial specialist liaison nurses. BMF 1999;318:683-4

24 Sever P, Beevers G, Bulpitt C, et al. Management guidelines in essential hypertension: report of the second working party of the British Hypertension Society. BMF 1993;306: party of

25 Ware J, Snow KK, Kosinski M, et al. SF36 Health survey: manual and interpretation guide. Boston: The Health manual and interpretation guide. Boston: The
Institute, New England Medical Center, 1993

26 Zigmond AS, Snaith RP. The hospital anxiety and Zigmond AS, Snaith RP. The hospital anxiety
depression scale. Acta Psychiatr Scand 1983;67:361-70.

27 Prochaska JO, Diclemente CC. The transtheoretical approach: crossing traditional foundations of change. Homewood: Don Jones/Irwin, 1984.

28 World Health Organiaation. Measuring obesity: classification and description of anthropometric data. Nutr UD, EUR/ICP/ NUT. Copenhagen: WHO, 1989:125

29 Jolly K, Bradley F, Sharp S, et al. Randomised controlled trial of follow up care in general practice of patients with myocardial infarction and angina: final results of the Southampton heart integrated care project (SHIP). The SHIP collaborative group. BMF 1999;318: 706-11.

30 Shaper AG, Pocock SJ, Walker M, et al. Risk factors for regional heart study. $\mathcal{F}$ Epidemiol Commun Health 1985;39: 197-209. 
31 Herlitz J, Haglid M, Albertsson P, et al. Short- and long-term prognosis after coronary artery bypass grafting in relation to smoking habits. Cardiogy 1997;88:492-7.

32 Lewin B, Robertson IH, Cay EL, et al. Effects of self-help post-myocardial infarction rehabilitation on psychological adjustment and use of health services. Lancet 1992;339: 1036-40

33 Llewellyn-Thomas H, Theil E, Paterson M, et al. In the queue for coronary artery bypass grafting: patients' perceptions of risk and 'maximal acceptable waiting time'. $f$ Health Serv Res Policy 1999;4:65-72.

34 Murray S. A nurse led clinic for patients with peripheral vascular disease. Br f Nursing 1997;6:726-8.
35 Garviscan L, Grimsay E, Littlejohns P, et al. Satisfaction with clinical nurse specialists in a breast care clinic: questionnaire survey. BMF 1998;316:976-7.

36 Steptoe A, Doherty S, Rink E, et al. Behavioural counselling in general practice for the promotion of healthy behaviour among adults at increased risk of coronary heart disease: randomised trial. BMF 1999;319:943-8.

37 Grampian asthma study of integrated care (GRASSIC) Integrated care for asthma: a clinical, social and economic evaluation. BMF 1994;308:559-64.

38 Greenhalgh PM. Shared care for diabetes, a systematic review. Occas Pap R Coll Gen Pract 1994:67:i-viii,1-35.

\section{IMAGES IN CARDIOLOGY}

\section{Penetrating heart injury from second world war}

A 74 year old man was admitted because of suspected liver cirrhosis with refractory ascites and impaired renal function. As a soldier in the second world war he was injured by an explosive bullet from a Russian sniper in 1942 near Leningrad. Since this event, a systolic murmur has been known. One year ago he started to complain about fatigue, weight gain, and an enlarged abdomen. On chest $x$ ray the right heart and the pulmonary arteries were enlarged with augmented pulmonary vascularisation. A large number of metal foreign bodies were seen. Transthoracic echocardiography showed enlargement of the right ventricle and right atrium, paradoxical septal movement, and severe tricuspid regurgitation with pulmonary hypertension. Colour Doppler revealed a turbulent high velocity jet between the left ventricle (LV) and the right atrium (RA) (below). This shunt was confirmed by cardiac ventriculography in left anterior oblique projection (top right) showing a rapid flow of contrast medium from the left ventricle to the right atrium (large arrow). Many metal fragments also were detected. One large fragment, which presumably caused the penetration, was found embed-

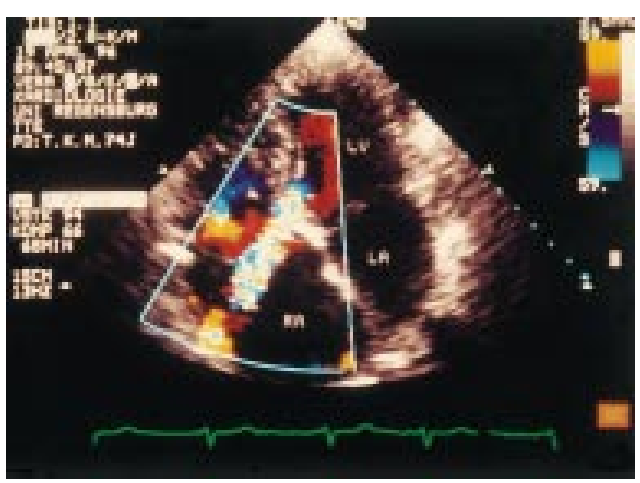

ded in the left posterior myocardial wall (small arrow). The left-to-right shunt amounted to $33 \%$ of pulmonary blood flow as determined by oximetry. In addition, coronary angiography showed a traumatic fistula between the enlarged right coronary artery and the right ventricle (bottom right, arrow). The patient underwent cardiac surgery successfully, with closure of a defect near the tricuspid annulus measuring $1 \mathrm{~cm}$ in diameter and closure of the coronary fistula.

DIETMAR ELSNER
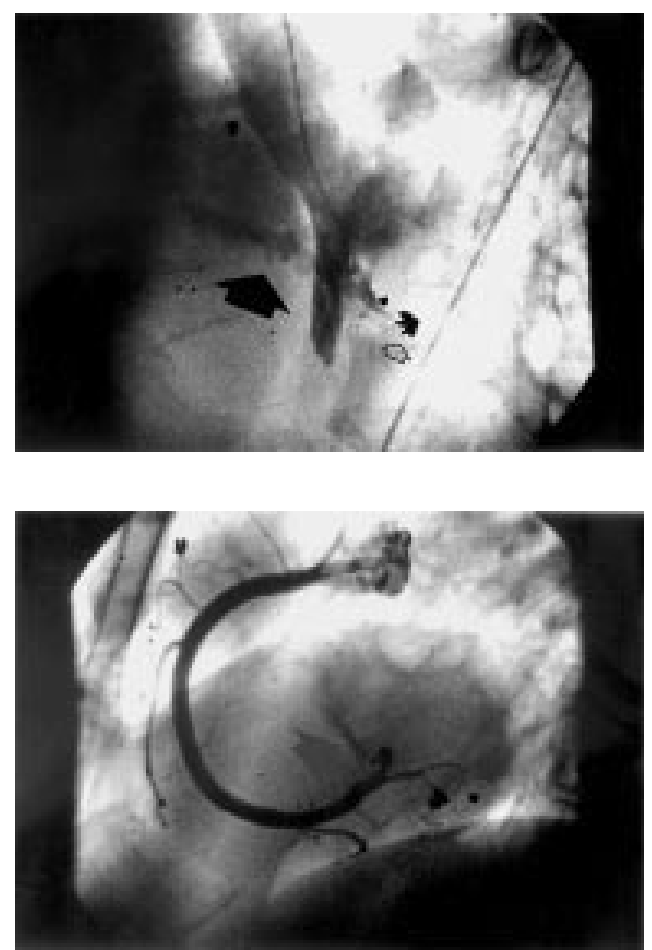